\title{
PENGEMBANGAN SISTEM PEMBELAJARAN PADA LABORATORIUM KOMPUTER BERBASIS LOCAL AREA NETWORK DI SMK NEGERI 4 KABUPATEN KAUR
}

\author{
Reno Supardi ${ }^{1}$, Devi Sartika ${ }^{2}$ \\ ${ }^{1,2}$ Dosen Tetap Program Studi Teknik Informatika Fakultas Ilmu Komputer Universitas Dehasen Bengkulu \\ Jl. Meranti Raya No. 32 Kota Bengkulu 38228 Telp. (0736) 22027, 26957 Fax. (0736) 341139 \\ e-mail:renosupardi00@gmail.com¹,devisartik@aunived.ac.id²
}

\begin{abstract}
The development of learning system is to change or repair existed learning system. The purpose is to help learning process and control the students. It focused on process and implementation result with development of learning system with net support school on computer lab with local area network base with planning system method NDLC (Network Development Life Cycle). The development of this learning system focusses on helping learning and control to find out the student development. Learning system is created by using Local Area Network connection.

Keywords: system development, Net support school, LAN
\end{abstract}

Intisari- Perkembangan Teknologi Informasi sangat berpengaruh terhadap kehidupan manusia sekarang. Banyak kegiatan yang dilakukan mengikutsertakan kemajuan teknologi itu sendiri. Sama halnya pada teknologi jaringan komputer yang terus bergerak maju seiring dengan perkembangan teknologi. Jaringan komputer saat ini merupakan suatu hal yang penting dalam sebuah perusahaan atau lembaga pendidikan, dengan adanya jaringan komputer kegiatan komunikasi yang dilakukan menjadi lebih mudah, efektif, hemat waktu dan masih banyak lagi keuntungan lain yang di dapat dengan adanya jaringan komputer, agar semua kegiatan yang dilakukan melalui jaringan komputer selalu berjalan dengan lancar tanpa adanya gangguan, jaringan tersebut harus senantiasa dipantau atau dimonitor.

Kata Kunci : Netsuppor School, LAN, Monitoring, Remote Desktop, Internet

\section{I.PENDAHULUAN}

Perkembangan teknologi informasi sangat berpengaruh terhadap kehidupan manusia sekarang. Banyak kegiatan yang dilakukan mengikutsertakan kemajuan teknologi itu sendiri. Sama halnya pada teknologi jaringan komputer yang terus bergerak maju seiring dengan perkembangan teknologi. Jaringan komputer saat ini merupakan suatu hal yang penting dalam sebuah perusahaan atau lembaga pendidikan, dengan adanya jaringan komputer kegiatan komunikasi yang dilakukan menjadi lebih mudah, efektif, hemat waktu dan masih banyak lagi keuntungan lain yang di dapat dengan adanya jaringan komputer, agar semua kegiatan yang dilakukan melalui jaringan komputer selalu berjalan dengan lancar tanpa adanya gangguan, jaringan tersebut harus senantiasa dipantau atau dimonitor.

Jaringan komputer adalah hubungan antara komputer, peripheral dan peralatan pendukung lainnya yang saling dihubungkan satu dengan yang lain untuk dapat dipergunakan secara bersama-sama. Jumlah komputer, peripheral dan peralatan pendukung lainnya yang dihubungkan satu dengan yang lain untuk dapat dipergunakan secara bersama-sama minimal 2 (dua) unit sampai dengan beberapa ratus unit. SMK Negeri 4 Kabupaten Kaur merupakan salah satu Sekolah Menengah Kejuruan Negeri yang terdapat di Kabupaten Kaur yang memiliki laboratorium komputer. Laboratorium Komputer pada SMK Negeri 4 Kabupaten Kaur sudah terhubung dengan topologi jaringan star. Namun walaupun sudah terhubung jaringan, pembelajaran yang berlangsung masih bersifat konvensional, guru menerangkan materi oleh karena itu, dalam penelitian ini akan dilakukan pengembangan dilaboratorium komputer dengan membangun sistem monitoring menggunakan net support, sehingga guru dapat memantau aktivitas yang sedang dilakukan oleh siswa pada masing-masing komputer yang terhubung di dalam jaringan.

Netsupport School adalah sebuah sistem atau aplikasi komputer yang dijalankan pada beberapa komputer yang terhubung dengan jaringan. Sistem Netsupport school ini sebuah aplikasi yang khusus diciptakan untuk membantu dalam proses pembelajaran dan pengawasan penggunaan komputer oleh siswa. Dengan aplikasi ini guru bisa 
memonitor seluruh tampilan layar siswa atau melihat program apa saja yang dijalankan oleh siswa. suatu aplikasi berbasis jaringan yang dapat mengelola data siswa, data materi, data tugas, serta kuis yang dilaksanakan di Sekolah.

\section{TINJAUAN PUSTAKA}

Laboratorium komputer adalah sarana yang digunakan untuk berlangsungnya praktikum komputer sebagai pendekatan pembelajaran Teknologi Informasi dan Komunikasi. Idealnya bukan hanya praktikum komputer yang dilakukan tetapi pembelajaran TIK berupa inovasi lain dari dunia komputer dari perkembangan zaman modern. Untuk menunjang pembelajaran inovasi modern tentunya harus di berikan fasilitas laboratorium komputer yang memadai sesuai standar ideal agar kegiatan pembelajaran efektif. Sehingga apa yang di pelajari dan di praktikkan peserta didik didapat penguasaan pengetahuan yang lebih luas lagi. (Ibrahim 2003 : 42).

Pemerintah sebenarnya sudah menetapkan standar ideal melalui kebijakan standar laboratorium dalam Permendiknas nomor 24 tahun 2007. Ruangan laboratorium yang ideal memiliki panjang $30 \mathrm{~m}$ dan lebar $5 \mathrm{~m}$ yang digunakan untuk 15 peserta didik dengan rasio minimum luas ruang laboratorium komputer adalah $2 \mathrm{~m} 2 /$ peserta didik. (Marpanaji 2014 : 68).

Untuk perabotan laboratorium terdiri dari kursi peserta didik 1 buah/peserta didik, meja 1 buah/2 peserta didik, kursi guru 1 buah/guru, meja guru 1 buah/guru. Sedangkan peralatan Pendidikan teridiri dari Komputer 1 unit/2 peserta, Printer 1 unit/lab, Scanner 1 unit/lab, Titik akses Internet 1 titik/lab, LAN sesuai banyak komputer, Stabilizer sesuai banyak komputer, dan modul praktek 1 set/komputer. (Ali 2009 : 3). Dengan menerapkan standar ideal fasilitas laboratorium komputer di sekolah yang ditetapkan oleh pemerintah sebenarnya belum memenuhi kriteria perkembangan di zaman modern. Masih banyak yang perlu di tambahkan untuk mencapai idelisme sejati sehingga pengetahuan yang didapat lebih luas lagi tidak sekedar praktikum komputer biasa. Perkembangan yang dapat diadopsi seperti perkembangan komputer dengan bentuk papan tulis fisik yang dapat dipakai oleh siswa untuk berkreatifitas menuangkan idenya khususnya dalam hal menggambar. Ada juga komputer yang bisa menampilkan simulasi secara nyata melalui virtual reality di ruang lab menggunakan handset virtual reality (VR) sehingga pembelajaran terasa lebih jelas dan menyenangkan. Tetapi masalahnya untuk memenuhi semua itu sebuah lab harus mengelurkan budget yang tidak kecil karena semuanya berasal dari peralatan yang canggih yang berkembang zaman modern ini (Jusak $2013: 85$ ).

Hal besar ini dapat dicermati oleh semua orang pelaku pendidikan terutama pemerintah dengan penerapan pada salahsatu sekolah model tidak perlu semuanya karea masih menjadi sebuah pemikiran yang bisa dicoba untuk kemajuan pendidikan yang sesuai perkembangan zaman modern.

\section{A. Jaringan Komputer}

Jaringan komputer adalah sekelompok komputer otonom yang saling menggunakan protokol komunikasi melalui media komunikasi sehingga dapat saling berbagi data, informasi, program aplikasi, dan perangkat keras seperti printer, scanner, CD-Drive ataupun harddisk, serta memungkinkan untuk saling berkomunikasi secara elektronik. Potensi jaringan komputer antara lain (Khasanah $2016: 183)$ :

[1] Mengintegrasikan berbagai peralatan jaringan komputer

[2] Komunikasi, jaringan komputer memungkinkan terjadinya komunikasi antar pemakai komputer

[3] Perlindungan Data dan Informasi, jaringan komputer dimanfaatkan pula untuk mendistribusikan proses dan aplikasi sehingga dapat mengurangi terjadinya bottleneck atau tumpukan pekerjaan pada satu bagian.

[4] Keteraturan Aliran Informasi, jaringan komputer mampu mengalirkan data-data komputer client dengan cepat untuk mengintegrasikan dalam komputer server.

Berdasarkan letak geografis jaringan komputer dapat dibagi menjadi tiga jenis yaitu:

[1] Local Area Network (LAN)

[2] Metropolitan Area Network (MAN) 


\section{[3] Wide Area Network (WAN)}

\section{B. Topologi Jaringan}

Topologi atau arsitektur jaringan merupakan pola hubungan antar terminal dalam suatu sistem jaringan komputer. Topologi jaringan adalah istilah yang digunakan untuk menguraikan cara bagaimana komputer terhubung dalam suatu jaringan. Topologi-topologi jaringan diantaranya sebagai berikut (Khasanah, 2016:183) :

\section{Client Server}

Arsitektur client server adalah suatu cara untuk meningkatkan kinerja konfigurasi file server yang menurun karena faktor skalabilitas (penambahan workstation dalam jumlah yang signifikan) (Mulyana, 2017, 129).

Pada dasarnya, Client server dibentuk oleh tiga komponen dasar, yaitu :

[1] Client : merupakan terminal yang digunakan oleh pengguna untuk meminta layanan tertentu yang dibutuhkan.

[2] Middleware : merupakan komponen perantara yang memungkinkan client dan server untuk saling terhubung dan berkomunikasi satu sama lain

[3] Server : merupakan pihak yang menyediakan layanan.

\section{Netsupport School}

Netsupport School adalah sebuah sistem atau aplikasi komputer yang dijalankan pada beberapa komputer yang terhubung dengan jaringan. Sistem Netsupport school ini sebuah aplikasi yang khusus diciptakan untuk membantu dalam proses pembelajaran dan pengawasan penggunaan komputer oleh siswa. Dengan aplikasi ini guru bisa memonitor seluruh tampilan layar siswa atau melihat program apa saja yang dijalankan oleh siswa. Dengan Netsupport School ini dapat melihat tampilan halaman menu utama dan aktivitas siswa (Yunistira, 2014:3).

\section{METODOLOGI PENELITIAN}

\section{A. Metode Penelitian}

Network Development Life Cycle (NDLC) merupakan model kunci dibalik proses perancangan jaringan komputer. Seperti model pengembangan sistem untuk aplikasi perangkat lunak, NDLC terdiri dari elemen yang mendefinisikan fase, tahapan, langkah, atau mekanisme secara spesifik. Dari kata "cycle" (siklus) adalah kata kunci deskriptif dari siklus hidup pengembangan sistem jaringan yang menggambarkan secara eksplisit seluruh proses dan tahapan pengembangan sistem jaringan yang terus berkelanjutan. Iswan (2010:45). dikarenakan tahap-tahap yang ada pada metode pengembangan NDLC, paling cocok digunakan pada penelitian ini. Yaitu penelitian yang berhubungan dengan jaringan membutuhkan tahap analisis, desain, implementasi, dan monitoring.

Dapat diketahui bahwa tahapan atau mekanisme yang digunakan dalam metode pengembangan NDLC tersebut adalah:

1). Analisa permasalahan yang muncul, analisa keinginan user, dan analisa toplogi jaringan yang sudah ada metode yang digunakan pada tahapan ini diantaranya adalah wawancara dan suvey langsung kelapangan.

2). Desain topologi dan sistem yang akan dibangun dalam tahapan ini desain dirancang berdasarkan data-data yang didapat sebelumnya.

3). Implementasi pada tahapan ini merupakan penerapan semua yang telah dirancang dan desain sebelumnya dalam tahapan ini sangat menentukan dari berhasil atau gagalnya project yang akan dibangun.

4). Monitoring adalah tahapan setelah tahapan implementasi yang merupakan tahapan yang sangat penting agar jaringan komputer dan komunikasi dapat berjalan sesuai dengan keinginan dan tujuan awal analisis.

\section{B. Analisa Sistem Baru}

Sistem yang akan dibuat yaitu melakukan pengembangan dilaboratorium komputer dengan membangun sistem monitoring menggunakan net support, sehingga guru dapat memantau aktivitas yang sedang dilakukan oleh siswa pada masing-masing komputer yang terhubung di dalam jaringan. 


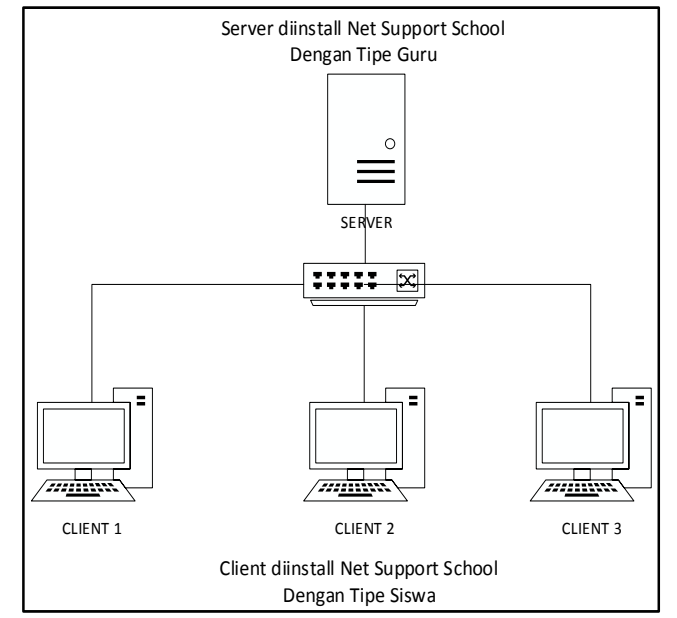

Gambar 1. Jaringan Yang Akan Dibangun

Pada Gambar 1 terlihat bahwa pada Laboratorium Sekolah disisi server akan diinstal Net Support School dengan Tipe Guru, sedangkan client diinstal dengan net support school dengan tipe siswa. Di sisi server (guru) dapat memantau kegiatan yang dilakukan oleh siswa yang telah masuk ke dalam jaringan yang sama.

\section{Metode Pengujian}

Pengujian merupakan bagian yang penting dalam pembangunan sebuah perangkat lunak, pengujian ditujukan untuk menemukan kesalahan-kesalahan pada sistem dan memastikan sistem yang dibangun telah sesuai dengan apa yang direncanakan sebelumnya. Pengujian dilakukan untuk menjamin kualitas dan juga mengetahui kelemahan dari perangkat lunak. Tujuan dari pengujian ini adalah untuk menjamin bahwa perangkat lunak yang dibangun memiliki kualitas yang handal, yaitu mampu mempresentasikan kajian pokok dari spesifikasi analisis, perancangan

\section{IV.HASIL DAN PEMBAHASAN}

Dari hasil pengembangan sistem pelajaran menggunakan NetSupportScool dalam penelitian ini, didapat beberapa hasil bagi Guru dan Siswa sebagai berikut :

1) Guru

a) Guru dapat memonitoring / memantau kegiatan yang dilakukan siswa pada saat pembelajaran berlangsung di laboratorium

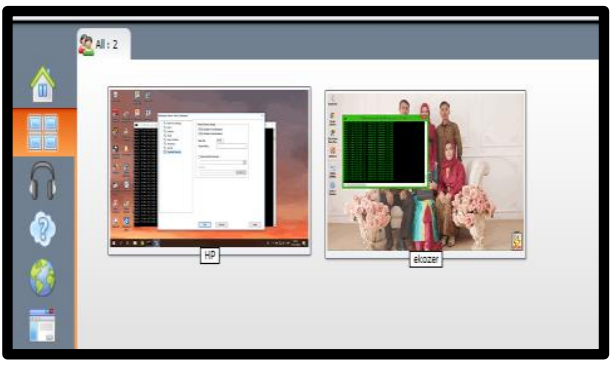

Gambar 2. Tampilan Monitoring Komputer Siswa

b) Guru dapat memberikan pesan seperti peringatan kepada salah satu komputer siswa yang tidak mengikuti proses pembelajaran yang sedang berlangsung

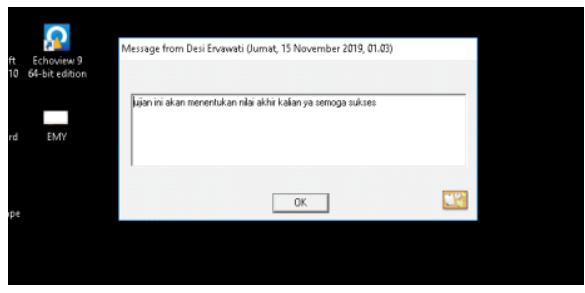

Gambar 3. Guru Memberikan Pesan Peringatan

c) Guru dapat mengirim atau mengambil file pada salah satu komputer siswa

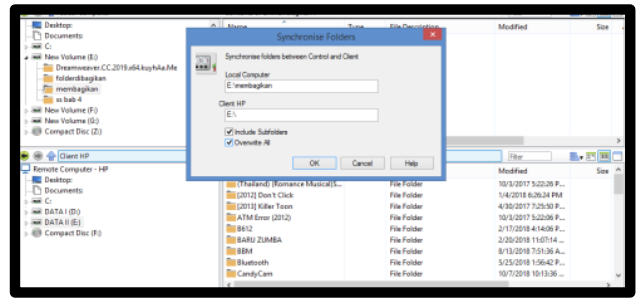

Gambar 4 Proses Pengambilan File

d) Guru dapat melakukan chat dengan siswa pada ruang chat yang telah disediakan

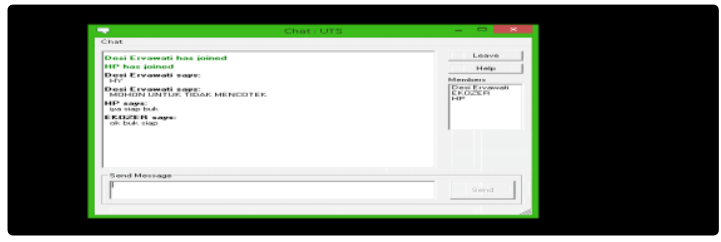

Gambar 5 Chating Komputer Guru Kepada Siswa

e) Guru dapat mematikan/reboot pada salah satu komputer siwa

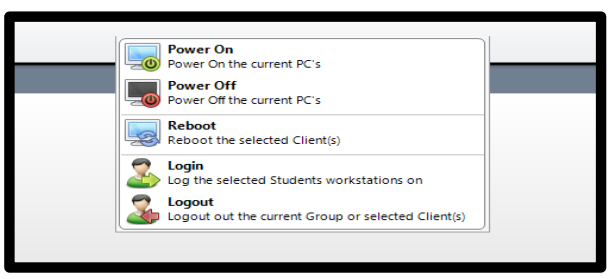

Gambar 6. Guru Mematikan Komputer Siswa 
2) Siswa

a) Siswa dapat mengakses ruang kelas yang telah dibentuk

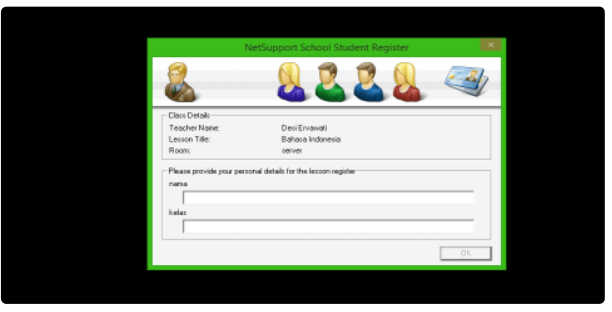

Gambar 7 Siswa Login Ruang Kelas

b) Siswa dapat membalas pesan pada ruang chat yang telah dibentuk

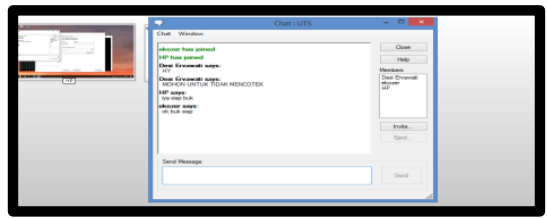

Gambar 8. Siswa Membalas Pesan

c) Siswa mendapatkan pesan khusus dari guru jika siswa tidak mengikuti pembelajaran yang sedang berlangsung di sekolah

Adapun jaringan yang telah dibangun, seperti Gambar 4.5 .

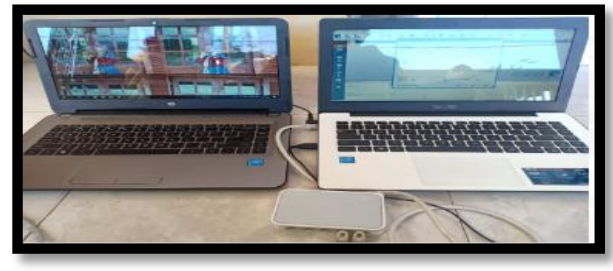

Gambar 9. Jaringan Yang Telah Dibangun

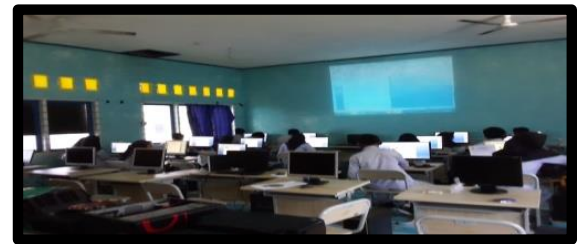

Gambar 10. Laboratorium Komputer

Pada gambar diatas dapat diketahui bahwa dalam simulasi penggunakan aplikasi ini menggunakan 2 Laptop yang sudah terhubung dengan kabel dan membentuk sebuah jaringan LAN dan menggunakan HUB sebagai media alat penghubungnya. Laptop sebelah kanan sebagai server dan kiri sebagai klien atau laptop siswa dan kedua laptop ini sudah menginstal aplikasi NetSupport School.

1. Menyiapkan Perangkat
Adapun perangkat yang digunakan dalam penelitian ini antara lain :

[1] Komputer yang akan dijadikan server

[2] 2 unit komputer yang akan dijadikan client

[3] 1 buah switch sebagai penghubung antara server dan client

[4] kabel UTP sebagai penghubung antara server dengan client

2. Melakukan Konfigurasi Jaringan

Setelah semua perangkat sudah siap, kemudian melakukan konfigurasi jaringan pada masing-masing laptop tersebut menggunakan IP Versi 4 dengan ketentuan sebagai berikut :

[1] Laptop Server dengan IP Address 192.168.1.1

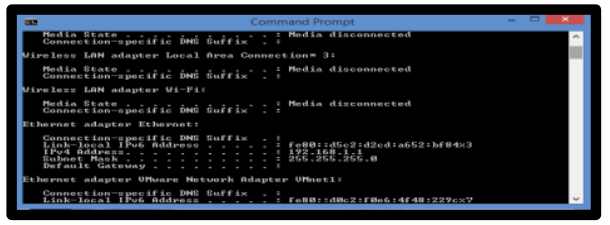

Gambar 11. IP Laptop Server

[2] Laptop Client dengan IP Address 192.168.1.2 sampai dengan 192.168.1.999

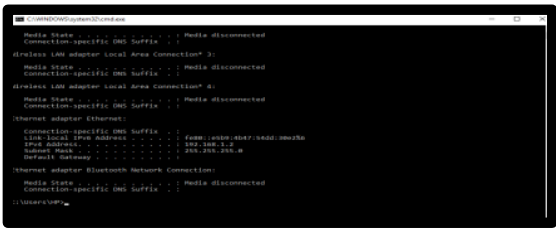

Gambar 12. IP Laptop Siswa

Setelah melakukan konfigurasi jaringan, dalam penelitian ini akan dibahas Net Support pada Guru dan Siswa, antara lain :

Melakukan install NetsupportSchool

Net Support Tipe Guru

Membuka aplikasi Net Support

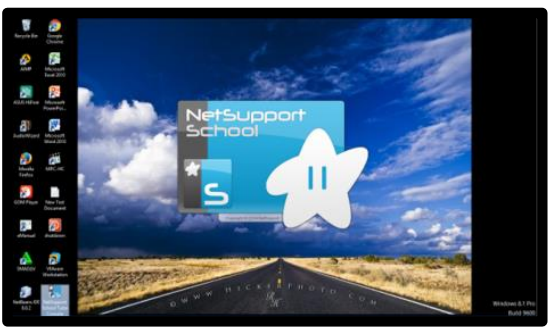

Gambar 13. Aplikasi Net Support School 
Pada Laptop Server dapat langsung membuka aplikasi Netsupport School yang ada di desktop

3. Melakukan Testing NetsupportSchool

Melakukan uji koneksi dari komputer server ke klien

Dengan mengetikan perintah ping ke ip komputer siswa yang akan dikoneksikan melalui aplikasi Netsupport School

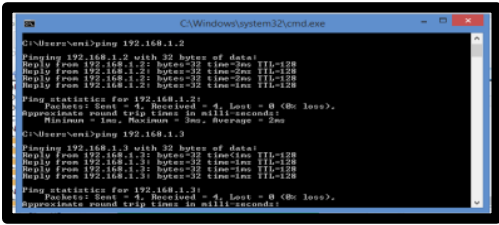

Gambar 14. Melakukan Uji Koneksi ke Komputer Siswa

Dalam pengujian ini berguna untuk mengettahui apakah komputer server sudah terhubung dengan komputer siswa atau belum sebelum menggunakan aplikasi Netsupport School ada baikknya melakukan tes ping. Kemudian membuka aplikasi NetsupportSchool.

Mengisi nama guru dan nama mata pelajaran yang akan diajarkan, seperti Gambar 4.3.

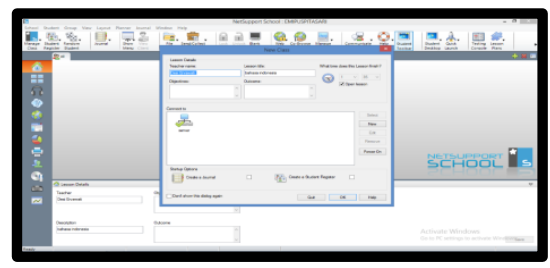

Gambar 15. Mengisi Nama Guru dan Mata Pelajaran

Pada form diatas terdapat beberapa textfield yang harus diisi oleh guru seperti nama guru mata pelajaran dan durasi waktu yang disediakan oleh guru kepada siswanya.

Mengidentifikasi client yang terhubung ke server, seperti Gambar 4.4.

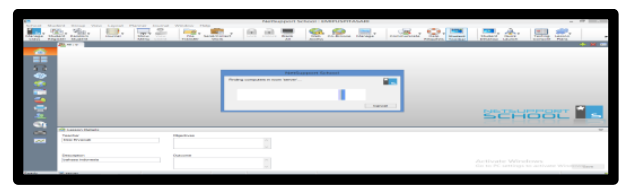

Gambar 16. Mengidentifikasi Client

Kemudian pada Folder Browse di pilih untuk mencari komputer Client dan lalu klik tombol OK. Maka komputer Server akan mencari Komputer Client didalam jaringan komputer. Setelah selesai maka akan diketemukan komputer Client. Jika ingin mengkoneksikan keseluruhan dari komputer Client maka langkah selanjutnya adalah blocking komputer Client kemudian klik kanan dan klik connect. Memonitoring client, seperti Gambar 4.5.

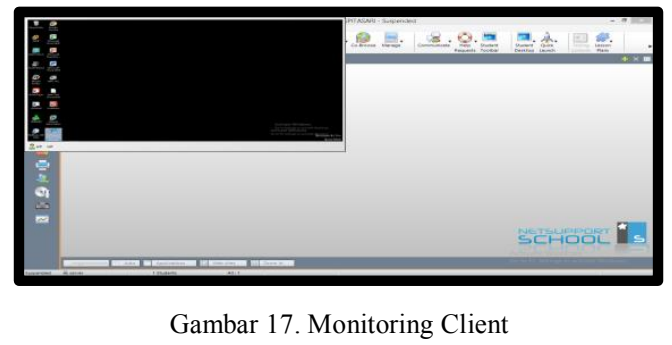

Setelah semua komputer Client terhubung dengan Netsupport Control, lalu klik Show pada toolbar yang ada di atas. Setelah menekan tombol Show maka akan muncul tampilan Desktop pada Komputer Server ke setiap Komputer Client. Setelah menekan tombol Show maka Anda dapat mengendalikan komputer-komputer Client yang sudah terhubung dengan jaringan. Kemudian jika pada Komputer Client akan disconnect maka tinggal di klik End Show pada Desktop yang letaknya dibawah sebelah kanan lalu remote desktop telah selesai.

Memberikan Pesan ke client, seperti Gambar 4.6.

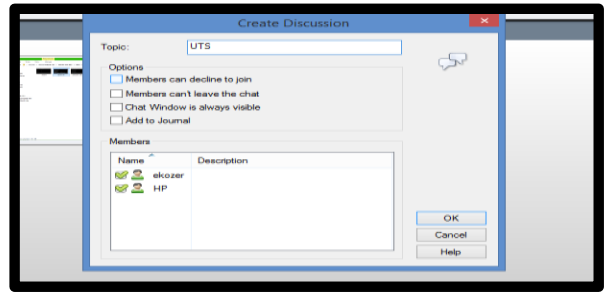

Gambar 18. Memberikan Pesan Ke Client

Pilih dahulu Komputer Client yang ingin diberikan sebuah message (informasi) kemudian pada menu Browse. Kemudian klik Komputer yang Anda pilih lalu klik kanan pada mouse dan tekan message. Setelah menekan tombol message kemudian langkah selanjutnya adalah memberikan informasi pada Komputer Client tersebut. Setelah informasi yang akan disampaikan pada Komputer Client telah ditulis maka hal selanjutnya adalah mengirim informasi dengan menekan tombol Send laluPengiriman informasi telah selesai. Mengirim File Ke client, seperti Gambar 4.7. 


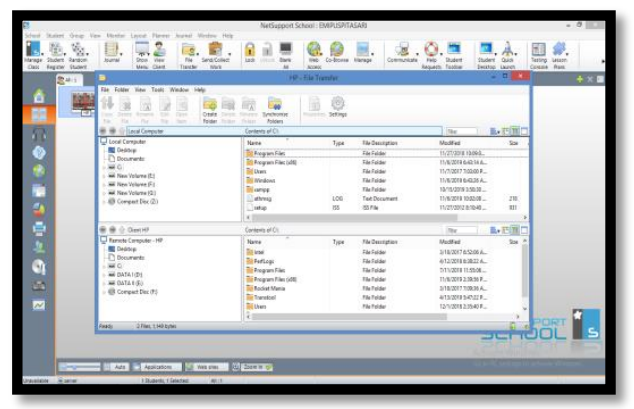

Gambar 19. Mengirim File Ke Client

Pada Folder Browse di pilih untuk mencari komputer Client dan lalu klik tombol OK. Maka komputer Server akan mencari Komputer Client didalam jaringan komputer. Setelah selesai maka akan diketemukan komputer Client.

Kemudian pilih Komputer Client yang akan ditransfer file(data) dan selanjutnya koneksikan Komputer Client tersebut. Setelah Komputer Client telah terhubung dengan Komputer Server maka langkah selanjutnya pada Toolbar diatas adalah mencari icon File Transfer. Kemudian diklik dan menentukan letak file (data) yang akan ditransfer. Kemudian tekan tombol OK dan pengiriman data sudah selesai. Membuka ruang chating antara guru dan siswa, seperti Gambar 4.8

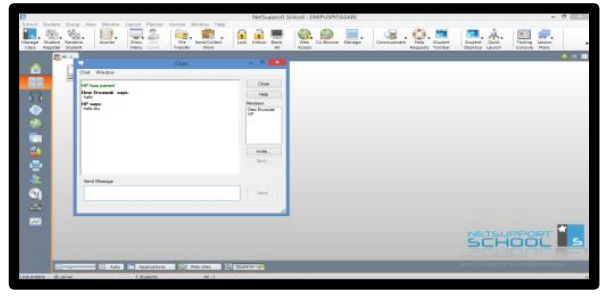

Gambar 20 Ruang Chating

Menghubungkan pada setiap komputer client yang akan dipakai untuk chatting. Dengan cara, mengoneksikan ke seluruh komputer client. Setelah semua komputer client telah tersambung atau terhubung dengan server, maka hal selanjutnya adalah memblok komputer client. Kemudian pada toolbar diatas, pada menu chat lalu tekan tombol chat dan setelah itu akan muncul gambar create discussion dan kemudian ketik topik yang akan dibicarakan. Klik ok dan semua komputer akan dapat berchatting dengan komputer yang lain. Jika chatting ingin mengakhiri program chatting antar komputer client, maka pada komputer server menekan tombol close pada komputer server.
Membuat Soal Ujian

Dalam penggunaan aplikasi Netsupport School ini salah satu fitur yang banyak dimanfaatkan adalah menggunakan aplikasi ini sebagai media ujian atau hanya sekedar latihan soal ketika waktu pembelajaran dengan menggunakan aplikasi Netsupport School maka ujian siswa akan terasa lebih menarik karena aplikasi sangat mudah digunakan ujian berbasis komputer ini sangat banyak manfaatnya adapun langkah-langkah membuat soal ujian :

[1] Klik start kemudian buka program net support school test designer

[2] Kemudian setelah tampilannya muncul masukan user name dan password, kemudian klik icon questions

[3] Setelah itu klik icon toolbar create, maka akan muncul tampilan create a question dan plih jenis soalnya lalu klik create

[4] Kemudian masukan soal beserta jawaban yang benar dan salahnya, lalu klik tombol next untuk melanjutkan

[5] Setelah itu maka akan muncul tampilan question resources, pada bagian ini anda dapat menambahkan objek gambar, audio, bahkan video, setelah itu klik next,

[6] Setelah itu akan muncul tampilan question details, kemudian klik create subject

Kemudian klik create topic dan jika sudah selesai klik finish.

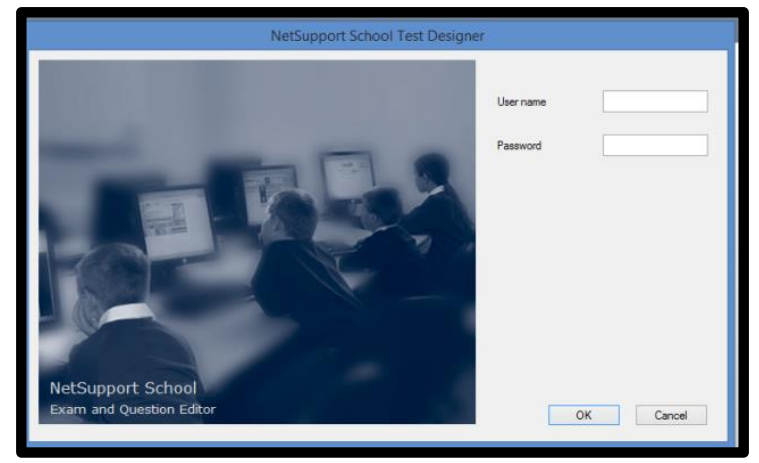

Gambar 21 Pembuatan Soal

\section{[1] Mematikan Komputer Siswa}

Kemudia fitur yang umum digunakan pada Netupport School lainnya adalah melakukan remote pada komputer siswa karena biasanya pada sebuah Lab komputer sekolah 
akan banyak sekali komputer maka pekerjaan itu akan terasa memberatkan dan terlalu memakan waktu maka dari itu dengan adanya aplikasi ini guru akan mudah mematikan seluruh komputer yang sudah digunakan oleh siswa dengan fitur shutdown pada aplikasi Netsupport School.

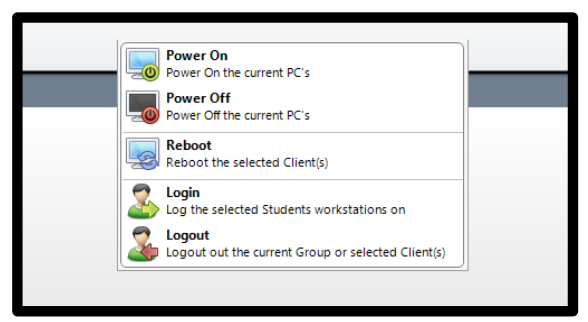

Gambar 22. Fitur Power Off Komputer Siswa

\section{Net Support Tipe Siswa}

[1] Mengakses ruang kelas yang telah dibentuk,

[2] Siswa dapat membalas pesan pada ruang chat yang telah dibentuk, seperti Gambar 4.10.

[3] Siswa mendapatkan pesan khusus dari guru, seperti Gambar 4.11.

Pesan pengumuman yang telah dibuat oleh server atau guru telah muncul di desktop klien dengan begitu guru tidak perlu repot untuk berbicara keras karena siswa akan membaca langsung pesan yang muncul pada komputernya masing-masing.

[4] Komputer siswa menerima data sharing

Data yang sudah di bagikan oleh komputer server akan masukan kedalam folder penyimpanan yang dituju kita hanya mencari folder yang sudah disharing oleh server.

[5] Melaksanakan ujian

Fitur soal yang biasa digunakan pada aplikasi Netsupport Scool selalu digunkan dalam ujian Lab sekolah dan soal-soal yang telah dibuat oleh server harus dikerjakan oleh siswa ketika ujian sesuai dengan ketentuan pengaturan oleh server.

Pengujian Sistem
Pada pengujian ini, akan diuji koneksi jaringan dengan cara melakukan ping pada command prompt

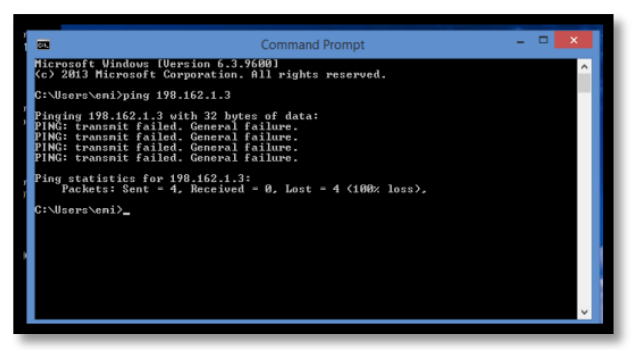

Gambar 23. Command Prompt

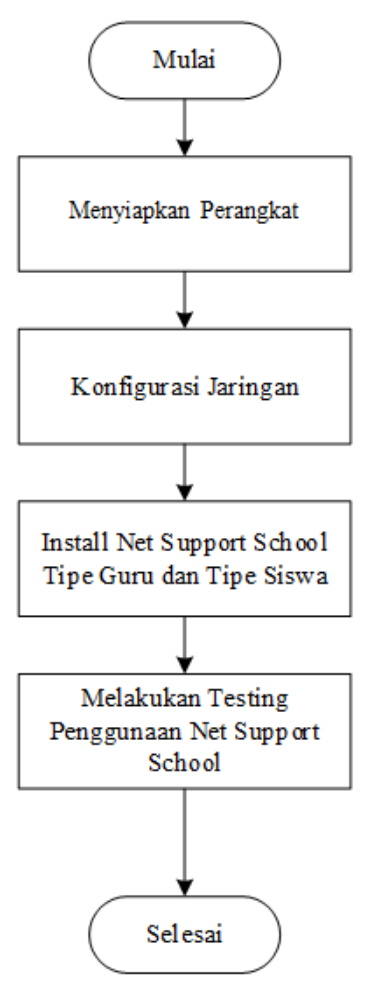

Gambar 24. Blokchart

\section{KESIMPULAN}

Jaringan komputer saat ini merupakan suatu hal yang penting dalam sebuah perusahaan atau lembaga pendidikan, dengan adanya jaringan komputer kegiatan komunikasi yang dilakukan menjadi lebih mudah, efektif, hemat waktu dan masih banyak lagi keuntungan lain yang di dapat dengan adanya jaringan komputer. Berdasarkan hasil dan pembahasan serta pengujian, maka dapat diambil beberapa kesimpulan yaitu: 
1. NetsupportSchool dapat mengembangkan sistem pembelajaran pada laboratorium komputer SMK Negeri 4 kabupaten Kaur.

2. Dengan adanya aplikasi NetsupportSchool pembelajaran menjadi lebih praktis dan efektif.

3. Beberapa fitur yang sangat berguna dari hasil pengujian yang telah dilakukan adalah komputer guru bisa melakukan pemantauan jaringan melalui desktop, Komputer server bisa menjalankan aplikasi ke semua komputer client. Tidak hanya itu komputer server juga bisa mengendalikan aktivitas yang dilakukan dikomputer siswa seperti mematikan komputer siswa jadi dengan adanya aplikasi ini akan sangat membantu melakukan perawatan dengan banyak komputer client. Pengembangan sistem pembelajaran yang telah dibangun ini layak digunakan berdasarkan hasil pengujian yang telah dilakukan.

\section{DAFTAR PUSTAKA}

[1] clement-o'brien k., polit d.f. \& fitzpatrick j.j. (2011). Journal of Nursing Management19.Innovativeness of nurse leaders. New York.

[2] Ibrahim, Bafadal. (2003). Manajemen Perlengkapan Sekolah Teori dan Aplikasinya. PT Bumi Aksara. Jakarta.

[3] Khasana, Fata Nidaul. 2014. Perancangan dan Simulasi Jaringan Komputer Menggunakan Graphical Network Simulator 3 (GNS3). Makalah Program Studi Teknik Informatika Universitas Muhammadiyah Surakarta.

[4] Ladjmudin, Al-Bahra Bin. 2005. Analisis dan Desain Sistem Informasi. Graha Ilmu. Yogyakarta.

[5] Marpanaji, Eko. (2014). Kontribusi Laboratorium Komputer, Internet dan Motivasi Berprestasi terhadap hasil Belajar Siswa RPL se-Kabupaten Bantul. Bantul. Jusak. (2013). Teknologi Komunikasi Data Modern. Andi Publisher. Yogyakarta.

[6] Mulyana, Redi. Ridwan, Mohamad. 2017. Aplikasi Penggajian Karyawan Berbasis Client-Server Pada PT.
Radio Nasional Buana Suara. Jurnal Ilmiah Ilmu Ekonomi Vol.5 Edisi 10 Maret 2017. ISSN 20886969.

[7] Santoso. Nurmalina, Radna. 2017. Perencanaan dan Pengembangan Aplikasi Absensi Mahasiswa Menggunakan Smart Card Guna Pengembangan Kampus Cerdas (Studi Kasus Politeknik Negeri Tanah Laut). Jurnal Integrasi Vol.9 No.1 April 2017. E-ISSN : 2548-9828

[8] Viktor Haryanto, Edy. 2012. Jaringan Komputer. Andi Offset. Yogyakarta.

[9] Wongkar, stefen. 2015. Analisa Impelementasi Jaringan Internet Dengan Menggabungkan Jaringan LAN dan WLAN di Desa Kawangkoan Bawah Wilayah Amurang II. Universitas Sam Ratulangi. Manado

[10] Yunistira, Niken. Dkk. 2014. Penerapan Aplikasi Netsupport School Terhadap Vasil Belajar Siswa Pada Mata Pelajaran Keterampilan Komputer dan Pengolahan Informasi (KPI) Di SMKN 5 Padang. Jurnal Universitas Bung Hatta Vol 1. No. I. 